\title{
Assisted delivery of mobile fetal head: a comparison of forceps, vaccum and assisted manual extraction of head at caesarean section
}

\author{
Sujata Swain*, N. Sagarika, Rabi N. Satpathy, Purna C. Mahapatra
}

Department of Obstetrics and Gynecology, S. C. B. Medical College Cuttack, Odisha, India

Received: 09 July 2017

Accepted: 05 August 2017

*Correspondence:

Dr. Sujata Swain,

E-mail: sjt_swain@yahoo.co.in

Copyright: () the author(s), publisher and licensee Medip Academy. This is an open-access article distributed under the terms of the Creative Commons Attribution Non-Commercial License, which permits unrestricted non-commercial use, distribution, and reproduction in any medium, provided the original work is properly cited.

\begin{abstract}
Background: Difficult fetal extraction occurs in 1-2\% of caesarean deliveries. Either forceps or a vaccum device is often used to assist in delivery of the fetal head in cesarean section in high floating/mobile fetal head. This study compare the safety (for mother and fetus) and efficacy of forceps and vacuum assisted delivery of high floating/mobile fetal head with the traditional method of manual extraction at caesarean section.

Methods: The sample size included 100 cases of LSCS with manual extraction of fetal head, 100 cases of LSCS with forceps assisted extraction of fetal head and 100 cases of LSCS with vacuum assisted extraction of fetal head.

Results: Application of fundal pressure was required in all cases of manual extraction group, in 51 cases of forceps extraction group. None of the cases of vacuum extraction group required application of fundal pressure. The U-D interval in manual extraction group was $90.56 \pm 4.91$ seconds, in forceps extraction group was 70.2 \pm 5.02 seconds and in the vacuum extraction group it was $62.3 \pm 2.03$ seconds. In the manual extraction group, there was an estimated blood loss of $428 \pm 69.38 \mathrm{ml}, 579 \pm 97.22 \mathrm{ml}$ of estimated blood loss was present in forceps extraction group and in the vacuum extraction group it was $454 \pm 66.92 \mathrm{ml}$.

Conclusions: This study reveals that with use of vacuum in CS for delivery of floating head, is superior than application of forceps and manual delivery in relation to time, blood loss and fundal pressure without any adverse effect on neonates and maternal complication.
\end{abstract}

Keywords: Caesarean Section, Forceps, High floating/mobile fetal head, U-D interval, Vacuum assisted delivery

\section{INTRODUCTION}

Cesarean section is the delivery of the viable fetus, placenta and membranes through an incision in the abdominal wall and the uterine wall. The estimated rate of CS is $15 \%$ worldwide during the past decade. A major technical problem of delivery by cesarean section is delivery of the fetal head through the uterine incision. Difficult fetal extraction occurs in $1-2 \%$ of cesarean deliveries. ${ }^{1}$ Either forceps or a vacuum device is often used to assist in delivery of the fetal head in cesarean section when the delivery is difficult and where atraumatic manual delivery of fetal head is not possible., ${ }^{2,3}$
High floating or mobile fetal head may be a spontaneous unengaged fetal head or following disengagement of a deeply impacted head. It has been a traditional concept that engagement of fetal head occurs by 38 weeks of gestation in primigravida. However, in multigravida, engagement always occurs after the onset of labour or even late in first stage of labour following rupture of membranes. Unengagement of head in primigravida has long been considered a possible sign of cephalo pelvic disproportion. ${ }^{4}$ The purpose of this study is to compare the safety (for mother and fetus) and efficacy of forceps and vacuum assisted delivery of high floating/mobile 
fetal head with the traditional method of manual extraction at cesarean section.

\section{METHODS}

This prospective cross sectional analytical study was done in the Department of Obstetrics and Gynecology, Sri Ram Chandra Bhanja Medical College, Cuttack, Odisha. The study was conducted from December 2014 to June 2016 on 300 cases of cesarean sections presenting with high floating fetal head at term. The sample size included 100 cases of LSCS with manual extraction of fetal head, 100 cases of LSCS with forceps assisted extraction of fetal head and 100 cases of LSCS with vacuum assisted extraction of fetal head. After taking informed consent and reassuring patients regarding expertise and confidentiality, those with floating fetal head at term undergoing CS were grouped into 3 groups. Group $\mathrm{M}$ included 100 cases of manual extraction, Group F included 100 cases of forceps extraction and Group V included 100 cases of vacuum extraction of floating head during cesarean section. All mothers received spinal anesthesia. All deliveries were timed using stopwatches from the time of entry into the uterus (amniotomy or herniation of the fetal membranes through the fully transected lower uterine segment) until the full delivery of the fetal head.

\section{Manual extraction of floating fetal head}

The physicians were instructed to incise the lower uterine segment and fetal membranes in the typical manner using the scalpel blade and by using the bandage scissors or by digital expansion. For those deliveries by means of traditional manual extraction, the physician's hand was introduced into uterus. Fundal pressure was given and lifting the anterior uterine wall with fingers facilitated fetal head delivery. If delivery was not imminent after one attempt at manual delivery, then it was proceeded with delivery by using forceps blades.

\section{Forceps assisted delivery of floating fetal head}

Short curved obstetric outlet forceps were used for fetal head extraction. Once the hysterotomy had been performed, one of the blades was introduced depending on the side (to make locking easier) so that it lied against the cheek infront of the anterior ear. The placement of the blade was facilitated by putting one hand under the head and sliding the blade between the fingers and thus moving the fetal head into position and was fixed. The other blade was then applied directly by lifting the anterior uterine wall with fingers thus sliding the blade into place. The shanks were locked. The correct position of the forceps was checked by making sure that the sagittal suture was oriented transversely between the blades. Adjustments were made as needed. Then traction was applied, without rotation, along the long axis of the mother. Fundal pressure was used to assist extraction. While guiding the head out of incision the vertex was flexedby digital pressure on the bones converging at the posterior fontanelle.

\section{Vacuum assisted delivery of floating fetal head}

The vacuum system used in our study comprised of a vacuum cup communicating with a source of vacuum. A soft, silicone obstetric vacuum cup of diameter- $6 \mathrm{~cm}$ (manufactured by Medisil Engineers, Iyyappanthangal, Chennai, Tamil Nadu) was used to evenly cover and adapt to the entire occiput and the individual fetal head contour. The hospital piped-vacuum supply with a vacuum regulator (SURGIX, High vacuum, MSYS007, Anand surgical industries, New Delhi, India) was used which required $300 \mathrm{~mm} \mathrm{Hg}\left(5.5 \mathrm{lb} / \mathrm{inch}^{2}\right)$ to develop the vacuum needed for ventouse delivery. This vacuum pressure was much less than the vacuum pressure used for assisted vaginal delivery(550-600 mm $\mathrm{Hg}$ ).Reading off the vacuum was calibrated in Full Vacuum $(300 \mathrm{~mm}$ $\mathrm{Hg}$ ), before connecting the vacuum cup to this suction line.

After the uterine incision and membranes rupture, the vacuum cup was placed over the occiput. When previously applied clamp was removed, the suction was immediately available and the vacuum cup was attached to the head. Fifteen to twenty seconds after, traction was applied concurrently with gentle fundal pressure, pulling towards the middle of the uterine incision. Holding the instrument near the base of the vacuum cup and gentle fundal pressure was helpful for completion of the procedure. Following delivery of the head, the vacuum was discontinued and the cup was removed. About 100 $\mathrm{mm} \mathrm{Hg}$ was sufficient to fix the cup to the fetal head.

\section{Criteria for proper application of vacuum cup}

The cup should be placed directly to fetal scalp as near the posterior fontanelle as possible and over the sagittal suture. The knob of the cup should be in the direction of the occiput. A finger is swept around the cup to ensure that no umbilical cord loops or any tissue is interposed between cup and head. Once vacuum is applied, the cup should not be twisted. During traction, pressure is applied with two fingers (thumb against the dome of the cup and index finger on the scalp in front of the cup) of the nondominant hand over the cup to maintain it in firm contact with the head and prevent cup detachment.

Fetal head delivery technique (Manual/Forceps/Vacuum), U-D interval (by stopwatch), blood loss for the procedure (by suctioning) was estimated. Presence of any complication like extension of uterine incision, cervical laceration, PPH were noted.

The general condition of the infant was assessed by the attending pediatrician. Fetal outcomes in terms of birth weight, neonatal APGAR scores (at 1 minute and 5 minute), evidence of any neonatal trauma (including scalp abrasions, bruising, cephalohematoma, subgaleal or 
intracranial hemorrhage) and need for neonatal resuscitation were observed.

\section{Statistical analysis}

The data were analyzed using the statistical software package. Statistical analysis included student t-test for continuous variables and chi-square test for categorical variables. Proportions were analyzed by z-test. Continuous data were analyzed and presented as Mean \pm Standard Deviation (SD) and categorical variables were presented as count. A p-value $<0.05$ was considered as statistically significant.

\section{RESULTS}

The total number of cases studied was 300.32 cases $(10.67 \%)$ were below 20 years of age. 258 cases $(86 \%)$ were between 20 to 30 years of age and 10 cases $(3.33 \%)$ were above 30 years of age.

Table 1: Comparison of mean maternal age among the groups.

\begin{tabular}{|llll|}
\hline Maternal age & Manual & Forceps & Vacuum \\
\hline Mean & 25.78 & 25.53 & 25.68 \\
\hline S.D. & 3.27 & 2.99 & 3.01 \\
\hline P-value & 0.581 & 0.725 & 0.834 \\
\hline
\end{tabular}

The Maternal age in the manual extraction group was $25.78 \pm 3.27$ years, in the forceps extraction group it was $25.53 \pm 2.99$ years and in the vacuum extraction group it was $25.68 \pm 3.01$ years.

Table 2: Comparison of maternal weight among study groups.

\begin{tabular}{|llll|}
\hline Weight (in Kg) & Manual & Forceps & Vacuum \\
\hline Mean & 64.98 & 65.56 & 64.95 \\
\hline S.D. & 1.75 & 2.48 & 1.13 \\
\hline P-value & 0.477 & 0.422 & 0.442 \\
\hline
\end{tabular}

The maternal weight in the manual extraction group was $64.98 \pm 1.75 \mathrm{~kg}$, in the forceps extraction group was $65.56 \pm 2.48 \mathrm{~kg}$ and in the vacuum extraction group it was $64.95 \pm 1.13 \mathrm{~kg}$. The maternal height in the manual extraction group was $1.51 \pm 0.04 \mathrm{~m}$, in the forceps extraction group was $1.56 \pm 0.01 \mathrm{~m}$ and in the vacuum extraction group it was $1.54 \pm 0.02 \mathrm{~m}$.

Table 3: Comparison of BMI among the study groups.

\begin{tabular}{|llll|}
\hline BMII $\left(\mathrm{Kg} / \mathrm{m}^{2}\right)$ & Manual & Forceps & Vacuum \\
\hline Mean & 28.39 & 26.87 & 27.27 \\
\hline S.D & 2.04 & 0.64 & 0.58 \\
\hline P-value & 0.339 & 0.470 & 0.391 \\
\hline
\end{tabular}

The BMI in the manual extraction group was $28.39 \pm 2.04$ $\mathrm{Kg} / \mathrm{m}^{2}$, in the forceps extraction group was $26.87 \pm 0.64$
$\mathrm{Kg} / \mathrm{m}^{2}$ and in the vacuum extraction group it was $27.27 \pm 0.58 \mathrm{Kg} / \mathrm{m}^{2}$.

Table 4: Gestational age.

\begin{tabular}{|llll|}
\hline GA (in weeks) & Manual & Forceps & Vacuum \\
\hline Mean & 39.04 & 38.84 & 38.63 \\
\hline S.D. & 0.51 & 0.50 & 0.43 \\
\hline P-value & 0.422 & 0.431 & 0.422 \\
\hline
\end{tabular}

The gestational age in the manual extraction group was $39.04 \pm 0.51$ weeks, in the forceps extraction group was $38.84 \pm 0.50$ weeks and in the vacuum extraction group it was $38.63 \pm 0.43$ weeks.

\section{Table 5: Apparent etiology of non-engagement.}

\begin{tabular}{|lll|}
\hline $\begin{array}{l}\text { Apparent etiology of } \\
\text { nonengagement }\end{array}$ & $\begin{array}{l}\text { No. of } \\
\text { cases }\end{array}$ & $\%$ \\
\hline Deflexed head & 84 & 28 \\
\hline Cephalo pelvic disproportion & 60 & 20 \\
\hline Loops of cord around neck & 15 & 5 \\
\hline Prelabour rupture of membranes & 12 & 4 \\
\hline No cause found & 129 & 43 \\
\hline N & 300 & 100 \\
\hline
\end{tabular}

No apparent etiology of non-engagement was found in 129 cases (43\%). Among the known causes, deflexed head was most commonly found to be present in 84 cases (28\%), followed by cephalopelvic disproportion in 60 cases $(20 \%)$, loops of cord around neck in 15 cases $(5 \%)$ and prelabour rupture of membranes in 12 cases $(4 \%)$.

Application of fundal pressure was required in all cases of manual extraction group. In 51 cases of forceps extraction group, application of fundal pressure was required and 49 cases did not require it. None of the cases of vacuum extraction group required application of fundal pressure. The U-D interval in manual extraction group was $90.56 \pm 4.91$ seconds, in forceps extraction group was 70.2 \pm 5.02 seconds and in the vacuum extraction group it was $62.3 \pm 2.03$ seconds. Extension of uterine incision was required in 12 cases belonging to the manual extraction group and 4 cases belonging to the forceps extraction group. None of the cases belonging to the vacuum extraction group required extension of uterine incision.

In the manual extraction group, there was an estimated blood loss of $428 \pm 69.38 \mathrm{ml}, 579 \pm 97.22 \mathrm{ml}$. of estimated blood loss was present in forceps extraction group and in the vacuum extraction group it was $454 \pm 66.92 \mathrm{ml}$. The birth weight in the manual extraction group was $3.03 \pm 0.21 \mathrm{kgs}$, in the forceps extraction group was $2.95 \pm 0.16 \mathrm{kgs}$ and in the vacuum extraction group it was $2.93 \pm 0.17 \mathrm{kgs}$. APGAR scores at $1 \mathrm{~min}$ was between 4 to 7 in 2 cases each in the manual, forceps groups the APGAR scores at $1 \mathrm{~min}$ was $>7$. The APGAR scores in Manual extraction group was 8 . vacuum extraction groups. In 98 cases each in the manual, forceps and 
vacuum extraction $47 \pm 0.54$, in forceps extraction group was $8.45 \pm 0.57$ and in the vacuum extraction group it was $8.6 \pm 0.53$. In all cases of the manual, forceps and vacuum extraction groups the APGAR score at 5 min. was $>7$. The APGAR score in manual extraction group was $8.49 \pm 0.50$, in the forceps extraction group was $8.53 \pm 0.50$ and in the vacuum extraction group it was $8.61 \pm 0.49$.

\section{DISCUSSION}

In the present study, there was no significant difference in the mean maternal age between Manual extraction and forceps extraction group $(\mathrm{P}=0.581)$, between Forceps extraction and Vacuum extraction group $(\mathrm{P}=0.725)$ and between Manual extraction and Vacuum extraction group $(\mathrm{P}=0.834)$. In the study done by Sritippayawan $\mathrm{S}$ et al, they observed no significant difference between the two groups $(\mathrm{P}=0.194)$ (Table 1). ${ }^{11}$

There was no significant difference in the maternal weight between the manual and forceps extraction groups $(\mathrm{P}=0.477)$, between the forceps and vacuum extraction groups $(\mathrm{P}=0.422)$ and between the manual and vacuum extraction groups $(\mathrm{P}=0.422)$.

Comparable to the study done by Sritippayawan $\mathrm{S}$ et al no significant difference between the two groups $(\mathrm{P}=0.864)$ (Table 2). ${ }^{3}$

In the present study, there was no significant difference in BMI between the Manual extraction and Forceps extraction group $(\mathrm{P}=0.339)$, between the Forceps extraction and Vacuum extraction group $(\mathrm{P}=0.470)$ and between the Manual extraction and Vacuum extraction group $(\mathrm{P}=0.391)$ (Table 3).

Study done by Arad I et al and Banu F et al showed that there was no significant difference in gestational age between the two groups. ${ }^{5,6}$

In the present study, there was no significant difference in gestational age between manual and forceps extraction groups $(\mathrm{P}=0.42)$, between forceps and vacuum extraction groups $(\mathrm{P}=0.43)$ and between manual and vacuum extraction groups $(\mathrm{P}=0.42)$ (Table 4$)$.

No apparent etiology of nonengagement was found in majority of cases studied by Ambwani B et al, Iqbal, S. et al and Nadia $\mathrm{K}$ et al.,7,8 No apparent etiology of nonengagement was found in the present study in majority of the cases (43\%) (Table 5).

In the study done by Arad I et al the U-D interval in the manual extraction group was $40.9 \pm 9.8$ seconds and in the Vacuum extraction group it was $79.4 \pm 10.2$ seconds. ${ }^{5}$ Sritippayawan $\mathrm{S}$ et al found the $\mathrm{U}-\mathrm{D}$ interval in the manual extraction and vacuum extraction group to be $86.3 \pm 53.9$ seconds and $65.3 \pm 31.2$ seconds respectively. ${ }^{2}$ The U-D interval in the manual and vacuum extraction

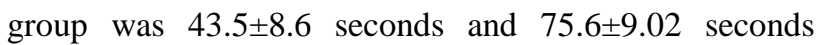
respectively, in the study done by Banu $\mathrm{F}$ et al. ${ }^{6}$ The difference in U-D interval was found to be significant in the studies done by Arad I et al $(\mathrm{P}<0.01)$, Sritippayawan, $\mathrm{S}$ et al $(\mathrm{P}<0.001)$ and Banu $\mathrm{F}$ et al $(\mathrm{P} \leq 0.0001)$.

Table 6: Comparison of U-D interval.

\begin{tabular}{|lllll|}
\hline U - D interval (Mean \pm SD) (Seconds) & M group & F group & V group & P - value \\
\hline Arad I et al & $40.9 \pm 9.8$ & - & $79.4 \pm 10.2$ & $<0.01$ \\
\hline Sritippayawan S et al & $86.3 \pm 53.9$ & - & $65.3 \pm 31.2$ & $<0.001$ \\
\hline Banu F et al & $43.5 \pm 8.6$ & - & $75.6 \pm 9.02$ & $<0.0001$ \\
\hline Present study & $90.56 \pm 4.91$ & $70.2 \pm 5.02$ & $62.3 \pm 2.03$ & $0.04,0.22$ and 0.01 \\
\hline
\end{tabular}

In the present study, we found the U-D interval in the manual extraction group as $90.56 \pm 4.91$ seconds, in the forceps extraction group as $70.2 \pm 5.02$ seconds and in the Vacuum extraction group it was $62.3 \pm 2.03$ seconds. The difference in U-D interval was significant $(\mathrm{P}=0.04)$ between manual extraction and forceps extraction groups. There was significant $(\mathrm{P}=0.01)$ difference in $\mathrm{U}-\mathrm{D}$ interval between Manual and Vacuum extraction groups. No significant $(\mathrm{P}=0.22)$ difference was observed in the U-D interval between the forceps and vacuum extraction groups (Table 6).

There was a significant difference in the estimated blood loss between the manual and forceps extraction group $(\mathrm{P}=0)$ and between the forceps and vacuum extraction group $(\mathrm{P}=0)$. The difference in estimated blood loss between the manual and vacuum extraction groups was not significant $(\mathrm{P}=0.99)$ (Table 7).

Table 7: Comparison of extension of uterine incision.

\begin{tabular}{|llll|}
\hline Extension of & M group & F & V \\
uterine incision & group & group \\
\hline Ross W et al & $16 \%$ & - & $0 \%$ \\
\hline Banu F et al & $13 \%$ & - & $7.1 \%$ \\
\hline Poordast T et al & $7.5 \%$ & - & $7.7 \%$ \\
\hline Present study & $12 \%$ & $4 \%$ & $0 \%$ \\
\hline
\end{tabular}

Percentage of cases, in the present study, who had extension of uterine incision in manual extraction group 
was similar to that of the study done by Ross $\mathrm{W}$ et al and Banu $\mathrm{F}$ et al. ${ }^{10}$ Similar to the study by Ross $\mathrm{W}$ et al, no case in the vacuum extraction group in our study had extension of uterine incision. There was no significant difference in the estimated blood loss between the manual and vacuum extraction groups $(\mathrm{P}=0.99)$. This was similar to the study of Sritippayawan S et al (Table 8).

Table 8: Comparison of estimated blood loss.

\begin{tabular}{|lllll}
\hline Estimated blood loss $($ Mean \pm SD) $(\mathrm{ml})$ & M group & F group & V group & P-value \\
\hline Sritippayawan S et al & $504.4 \pm 204.9$ & - & $576.7 \pm 182.9$ & 0.306 \\
\hline Present Study & $428.0 \pm 69.38$ & $579.0 \pm 97.22$ & $454.0 \pm 66.92$ & 0,0 and 0.99
\end{tabular}

Table 9: Comparison of APGAR score at $1 \mathrm{~min}$.

\begin{tabular}{|lllll|}
\hline APGAR Score at 1 min & M group & F group & V group & P - value \\
\hline Arad I et al & $8.5 \pm 0.3$ & - & $7.6 \pm 0.7$ & N.S. \\
\hline Banu F et al & $5.83 \pm 1.20$ & - & $5.67 \pm 1.12$ & 0.26 \\
\hline Present study & $8.47 \pm 0.54$ & $8.45 \pm 0.57$ & $8.6 \pm 0.53$ & $0.80,0.07$ and 0.09 \\
\hline
\end{tabular}

No significant difference in birth weight was present between manual and forceps extraction groups $(\mathrm{P}=0.999)$, between forceps and vacuum extraction groups $(\mathrm{P}=0.890)$ and between manual and vacuum extraction groups $(\mathrm{P}=1)$, which is similar to the study of Arad, Sritippayawan and Banu.
There was no significant difference in APGAR scores at 1 min between the manual and forceps extraction groups $(\mathrm{P}=0.804)$, between the forceps and vacuum extraction groups $(\mathrm{P}=0.070)$ and between the manual and vacuum extraction groups $(\mathrm{P}=0.096)$ which is similar to the findings of Arad and Banu (Table 9).

Table 10: Comparison of APGAR score at $5 \mathrm{~min}$.

\begin{tabular}{|lllll|}
\hline APGAR Score at 5 min & M group & F group & V group & P-value \\
\hline Arad I et al & $9.7 \pm 0.2$ & - & $9.9 \pm 0.1$ & N.S. \\
\hline Banu F et al & $7.59 \pm 0.83$ & - & $7.48 \pm 0.99$ & 0.29 \\
\hline Present study & $8.49 \pm 0.50$ & $8.53 \pm 0.50$ & $8.61 \pm 0.49$ & $0.55,0.20$ and 0.07 \\
\hline
\end{tabular}

Table 11: Comparison of fetal outcomes among study groups.

\begin{tabular}{|llll|}
\hline Fetal outcome & Manual & Forceps & Vacuum \\
\hline $\begin{array}{l}\text { Scalp injury } \\
\begin{array}{l}\text { Meconium } \\
\text { aspiration }\end{array}\end{array}$ & 0 & 2 & 0 \\
\hline $\begin{array}{l}\text { Neonatal } \\
\text { resuscitation }\end{array}$ & 73 & 75 & 70 \\
\hline $\begin{array}{l}\text { Admission to SNCU } \\
\text { Convulsion }\end{array}$ & 4 & 1 & 1 \\
\hline $\begin{array}{l}\text { Any intracranial } \\
\text { haemorrhage }\end{array}$ & 0 & 0 & 0 \\
\hline Early neonatal death & 0 & 0 & 0 \\
\hline
\end{tabular}

Similar to the findings of Arad and Banu, in the present study, the difference in the APGAR score at 5 min was not significant between the manual and vacuum extraction groups $(\mathrm{P}=0.07)$ (Table 10).
Similar to the study of Sritippayawan $\mathrm{S}$ et al and Poordast $\mathrm{T}$ et al, there was no Scalp injury in the manual and vacuum extraction groups in the present study (Table $11) ., 9$

Other intra-operative parameters such as failure, difficulty and switchover to other method of fetal head extraction were also studied. With proper application of forceps blades no such problem was faced. Similarly, with the soft silicone cup and hospital supplied vacuum regulator no pop-off of vacuum cup was observed. Postop maternal and neonatal outcomes were observed and no major morbidities were reported in subsequent follow up after 6 weeks.

\section{CONCLUSION}

This study reveals that with use of vacuum in CS for delivery of floating head, is superior than application of forceps and manual delivery in relation to time, blood 
loss and fundal pressure without any adverse effect on neonates and maternal complication With appropriate training, available soft silicone vacuum cup (preferable) can be valuable tools in the armamentarium of the practicing obstetric care providers to effect safe and effective method of delivery of high floating head at CS.

Funding: No funding sources Conflict of interest: None declared

Ethical approval: The study was approved by the Institutional Ethics Committee

\section{REFERENCES}

1. Levy R, Chernomoretz T, Appleman Z. Head pushing versus reverse breech extraction in cases of impacted fetal head during cesarean section. Eur J Obstet Gynecol Reprod Biol. 2005;12:24.

2. Sritippayawan S, Chantrapitak W. Assisted delivery of high floating fetal head: a comparison of vacuumassisted delivery with manual extraction. Asian Biomed. 2011;5:699-703.

3. Hankins GDV, Clark SL, Cunningham FG, Gilstrap LC. Operative Obstetrics, Norwalk: Appleton and Lange; $1995: 318$.

4. Ambwani BM. Primigravida with floating head at term or onset of labour. Internet J Gynecol Obstet. 2003;3(1).
5. Arad I, Linder N, Bercovici B. Vacuum extraction at cesarean section neonatal outcomes. J Perinatal Med. 1986;14:137-40.

6. Banu F, Pandit U, Ahmad S, Singh G. Effectiveness of vacuum extraction during cesarean section: A pioneer pilot study. SJMPS. 2016;2(10):4.

7. Iqbal S, Sumaira S. Outcome of primigravida with unengaged versus engaged fetal head at term or onset of labour. Biomedica. 2009;25:159-162.

8. Khurshid N, Sadiq F. Management of primigravida with unengaged head at term. PJMHS. 2012;6(1):369.

9. Poordast T, Tahereh T, Athar R, Fatemeh SN, Elham A. Vacuum extraction in cesarean delivery: an analysis of maternal and neonatal outcomes. Int $\mathbf{J}$ Develop Res. 2016;06(7):8656-8.

10. McQuivey RW, LaPorte V, Vecca A. Vacuum assisted delivery of the fetal head at cesarean section. In $1^{\text {st }}$ Beijing International Conference on Obstetrics and Gynecology, Beijing; 2005:7-10.

Cite this article as: Swain S, Sagarika N, Satpathy RN, Mahapatra PC. Assisted delivery of mobile fetal head: a comparison of forceps, vaccum and assisted manual extraction of head at caesarean section. Int $\mathbf{J}$ Reprod Contracept Obstet Gynecol 2017;6:4065-70. 